\title{
The Application of Triz in the Cultivation of Innovative Management Ability of the Administrative College Students
}

\author{
Xu Moli \\ Doctor, College of Finance and Trade, Ningbo Dahongying University, Ningbo City, Zhejiang \\ Province, China. \\ E-mail: xumoli521@126.com
}

\begin{abstract}
Keywords: TRIZ theory; economics and management college students; innovative management capabilities
\end{abstract}

\begin{abstract}
TRIZ as an international systematic innovation method, its innovative thinking has a significant impact on cultivating innovation management ability and optimizing innovation path. This paper expounds the basic principles and methods of TRIZ theory, analyzes the practical significance of innovative thinking of TRIZ theory to the cultivation of innovative management ability of economic and Management College students, summarizes the existing problems in the process of cultivating their innovative management ability, and puts forward corresponding suggestions to improve their innovative management ability.
\end{abstract}

\section{Introduction}

At present, China has entered the deep-waters of reform and development, the key period of economic transformation, the key to break through the bottleneck of economic development lies in innovation. In order to integrate innovation into all levels of social production, it is inseparable from the continuous efforts of innovative talents under the new era. In this era of high-speed development of information technology, innovation can not only stay in pursuit of a technological breakthrough, but from the management to optimize the innovation process, in order to improve the overall efficiency of innovation. College students, as the main force of innovation with high knowledge level, bear the key task of innovation and development in the whole society, in which engineering students have the characteristics of high professionalism and operability in the process of innovation, and there are more case support and experience in innovation education and concrete application technology innovation. Compared with this, the economics and management college students in the university curriculum system knowledge is more abstract, lack of concrete practice and operation, how to give full play to the students of management of the theoretical knowledge ability, cultivate their innovative thinking, improve their ability to innovate, is the current government, colleges and enterprises and other common problems. The term of innovation 
management is no longer unfamiliar, our country scholar has carried on the systematic analysis research to the innovation management, in which Xuqingrui and so on pointed out that the comprehensive innovation management mainly takes the various related innovation factors as the means to manage the new paradigm [1]. However, how to improve the innovative management ability and give full play to their professional advantages of economics and management college students is still a new problem, TRIZ theory of innovative thinking is one of the innovative ways to help solve this problem. It originated in the Soviet Union and was proposed by Achishule, the inventor of the Soviet Union. The first Achishule proposed the TRIZ theory and the corresponding theoretical system, but this is limited to the preliminary study, and later with the disintegration of the Soviet Union into the Western countries, to the world, through the exploration of many experts and scholars and gradually improve [2] . TRIZ theory was originally applied in the technical field, by using the innovative tools and methods in the TRIZ theory system to solve the innovation problem, and then gradually developed into various fields, including management field.

\section{Materials and Methods}

\subsection{The basic principles and methods of TRIZ theory}

TRIZ theory is an international systematic innovation method. It has a series of innovative tools and methods. Many well-known enterprises at home and abroad have used TRIZ theory to innovate. In addition, one of the key features is that it can directly hit the contradictions in the process of innovation, from the source of the problem to complete the solution; its specific innovative tools and methods include: ARIZ algorithm, contradiction matrix, 39 engineering parameters and 40 basic principles, the Object-field analysis method and the final ideal solution [3] . In the process of practical application of TRIZ theory, firstly, it is necessary to abstract and standardize the specific problems that need to be solved, which is mainly based on the constant description and standardization of the problem by the innovators. Secondly, the innovator should correspond the transformed TRIZ problem with its innovative tools and methods, find out the specific solving tools to get the TRIZ solution of the innovative problem, and then transform it into a specific solution according to the actual situation encountered in the process of innovation.

\subsection{The practical significance of applying TRIZ theory innovation thinking to the cultivation of innovative management ability of Economics and Management College Students}

\subsubsection{Define innovative management Ideas}

The creative thinking of TRIZ can help the College Students of economics and management to break the traditional thinking concept, switch the thinking mode, break through the thinking inertia, avoid the mistake that still relies on the old idea for the new problem, and provide the direction for solving the innovation problem. At the same time, the application of TRIZ theory in the process of innovation management can help the College Students of economics and management to solve the problem of concrete innovation, clarify the clue, clear the problem thinking, integrate the innovation process, manage the innovation process in an orderly way, and provide the guiding countermeasures for the further integration and management of the innovation process of the enterprise[4].

\subsubsection{Shorten innovation management time}

One factor in innovation is innovation efficiency. Efficiency on the one hand emphasizes the 
need to ensure the quality of innovation. At the same time it pay more attention to the speed of innovation. Through the whole process of innovation management, it can effectively shorten the time for innovation management. The innovative tools and methods of TRIZ theory provide effective guidance for this purpose. If the college students of economics and management can deeply understand the theoretical system of TRIZ and master its innovative tools and methods, they will be able to analyze the root causes of the problems and find the contradictions accurately in the specific innovative practice. This is a more systematic, accurate and in-depth analysis of the internal contradictions of traditional innovative approaches that have relied primarily on experience in the past, saving time while reducing resource waste, and thus advancing the orderly operation of the entire innovation process.

\section{Discussion}

Cultivating existing problems The innovative thinking of TRIZ theory and the systematic innovation tools and methods are the effective means to carry out the innovation management of the enterprises and institutions, through analyzing the basic principles and methods of TRIZ theory and their innovative thinking, to understand its important practical significance in economic development and social development. However, the current economics and management college students' innovative management concepts are not strong and the degree of mastery is not ideal. The specific performance in:

\subsection{Lack of self-innovation management consciousness}

With the rapid development of information today, under the background of the upsurge of the Internet + information network, innovation has entered an era of blowout development. It is becoming the mainstream of the society with its unique personality and charm. Faced with the increasingly competitive market, increasing employment pressure, compared to science and engineering in the technically non-dominant economics and management college students should pay attention to the cultivation of innovative managerial ability, which is the inevitable choice under the background of the innovation era. However, most college students of economics and management are lack of innovative consciousness, and even do not know much about innovation. They think that innovation is only the patent of science and engineering students, ignoring the management of innovation, and then continue to innovate in the management process. The lack of awareness of innovation and the lack of consciousness have a direct impact on the improvement of the ability of innovation management, which restricts the basic knowledge of the theory to exert practical benefit in practice.

\subsection{Limitations in the training process of colleges and universities}

Colleges and universities are the main body to train and improve the innovation management ability of college students. Under the background of the government policy support and the active response to innovation in the community, most colleges and universities have a certain understanding of cultivating the ability of innovation management of college students, but still in the initial stage, there are still many shortcomings. On the one hand, it is a problem of theoretical teaching. Most colleges and universities have carried out a certain number of innovative education courses, but the problem is that the setting of these courses is unreasonable, lack of pertinence, and it is difficult to meet the current market demand for innovative management ability of economic and management college students. On the other hand, it is practical teaching. Nowadays, most colleges and universities lack innovation bases. Especially for students majoring in economics and 
management, theoretical knowledge has not been better integrated with practical operation. The cultivation of innovation management ability mostly stays at the stage of theoretical explanation, so it is difficult to open up their innovative thinking and their innovative management ability can not be better trained.

\section{Conclusions}

\subsection{Create a good atmosphere for innovation}

A good innovation atmosphere can provide a good living space for TRIZ theory, so that more and more students of economics and management will understand TRIZ theory, study TRIZ theory, apply TRIZ theory flexibly, and analyze the problems encountered by this systematic and innovative method, and find out the root of the contradiction, then use the innovative tools and methods to find out the optimal solution of the problem. To create a good atmosphere of innovation requires the joint efforts of all sectors of society. On the one hand, the government and schools should increase their efforts to encourage and encourage students to innovate and attach more importance to the innovative management ability of students majoring in economics and management. On the other hand, the network from the media and all sectors of society should strengthen the publicity of innovation, so that the wind of innovation more in-depth into the economic and Management College students.

\subsection{Optimizing Innovative Education Courses}

On the one hand, a special TRIZ theory course should be set up to explain the TRIZ theory system and the application of specific innovative tools and methods in management by special TRIZ trainers, so as to enhance the innovative management ability of economics and management college students. On the other hand, it is necessary to integrate TRIZ theory with the professional theory it has learnt, and integrate it into every course, experiment and graduation design of the fouryear economic and management undergraduates, so as to cultivate the students' ability to standardize practical problems into TRIZ problems and the ability to solve problems by using TRIZ theory.

\section{References}

[1] Xu Qingrui, Zheng Gang, Cheng Jing. On the Total Innovation Management: A New Paradigm of Innovation Management-Theoretical origin and framework [J] Journal of management, 2006(2):135-142.

[2] Jiang Yanan, Jia Renfu, The Theory of TRIZ and It's Research Methods for Solving Problems [J] Chinese High Technology Enterprises 2017 (1) :68-69.

[3] Zhang Yixiang,Cui Jia,Tang Xin, Research on The Application of TRIZ Theory in The Cultivation of College Students' innovation and Entrepreneurship Ability [J] Human resource management,2017(1):152.

[4] Liang Qiuyan,Jiang Yongcheng,Qu Ailing, Application and Practice of TRIZ Theory in The Training Project of College Students' innovation and Entrepreneurship [J] High Education Forum,2016(8):122-124.

[5] Li Fuxing, Research on Training Mode of Innovative Talents Based on TRIZ theory [J] Higher Education Journals, 2016(17):33-35.

[6] Hui Ronggui, Luo Haorong, Dai Jiande, Reflection on The Implementation of TRIZ's Innovative Thinking in Agricultural Science and Technology [J] Agricultural Science and Technology Management, 2013(1):53-55.

[7] Long Jingiao, Liu Zhenzhen, Luo Zhirong,et al, Application of TRIZ Theory in Innovative Teaching of Organic Chemistry Experiment[J] Higher Education Journals,2017(4):34-35. 